\title{
Optimization of Cold Flow Properties of Biodiesel by Addition of Cold Flow Improver
}

\author{
Wong Yuin Yin, Saharudin Haron* \\ Centre of Hydrogen Energy, School of Chemical and Energy Engineering, Faculty of Engineering, \\ Universiti Teknologi Malaysia, Johor Bahru 81310, Johor, Malaysia \\ *Corresponding author: saharudinh@utm.my
}

\author{
Article History \\ Received: December 08, 2020 Received in revised form: Januari 06, 2021 Accepted: Januari 31, 2021 Published Online: June 30, 2021
}

\begin{abstract}
Despite the renewable and sustainable characteristics, biodiesel is poor in cold flow property (CFP) which causes a significant drawback that have limited its application. Thickening or crystallization of biodiesel in low temperature can readily result in the clogging of fuel pipes and fuel filters. The purpose of this study is to determine the optimum properties of blended biodiesel that gives the most accurate simulation results of blended biodiesel's CFP. TmoleX18 and COSMOthermX were used to identify the viscosities and densities of pure palm oil biodiesel and pure ethanol under different temperatures. The densities, viscosities and pour points of ethanol blended biodiesel was then calculated by using Grunberg-Nissan and, Riazi and Daubert equations. The simulation results were obtained under different compositions of ethanol added from 0 to 0.2 mole fraction at temperature range of $30{ }^{\circ} \mathrm{C}$ to $-5{ }^{\circ} \mathrm{C}$. The optimum combination of viscosities and densities of blended biodiesel for the blended cold flow properties was at $10{ }^{\circ} \mathrm{C}$ and $30{ }^{\circ} \mathrm{C}$ respectively. The simulation error at 0.1 mole fraction of ethanol was $0.92 \%$.
\end{abstract}

Keywords: Biodiesel, Ethanol, Cold Flow Properties, Optimization, Pour Point.

\subsection{INTRODUCTION}

Rapid industrialization has inevitably caused the world today to face crises of depletion of fossil fuels as the demands of diesels are increasing, which further leads to environmental deterioration [1]. To be the alternative sources for petroleumbased fuels, it must fulfill the characteristics of environmentally friendly, technically feasible and readily available [2]. Therefore, biodiesel which derived from vegetable oil or animal fats, is introduced as alternative for petroleum-based diesel as it has very similar characteristics of diesel, but it also has renewable, biodegradable and environmentally acceptable profile [3].

Despite the attributes of biodiesel have been proven to be a substitute of petroleum fuel, poor CFP has caused some significant drawbacks that have limited its application. CFP, an important performance indicator for diesel fuel, is important in maintaining a normal supply of fuel for engines and to the storage and transportation of diesel at low temperatures. There are a few crucial parameters for CFP such as cold filter plugging point (CFPP), cloud point (CP), solidification point (SP) and pour point (PP) [4]. Poor in CFP results in thickening of biodiesel at low temperature, causing fuel starvation and clogging of filters [5].

Therefore, the researchers introduce cold flow improver (CFI) to solve the concern of using biodiesel in winter countries. Olefin-ester copolymers (OECP), ethylene vinyl acetate copolymer (EACP) and polymethyl acrylate (PMA) [5], polymethyl acrylate (PMA) [6], methyl oleate (MO) [7], ethylene vinyl acetate copolymer (EVAC) [8], ethyl acetoacetate [9], and butanol [10] are the examples of the CFIs studied by the scholars. Despite many studies has been proved that the effectiveness in improving CFP of biodiesel by using CFI, it still remains as a challenge to achieve and implement as it needs more data to further investigate. However, the available data related to concentration of CFI and PP is still quite limited as previous research only focused on certain concentrations and conditions to test the effectiveness of CFI in 
improving CFP of biodiesel. Therefore, the objectives of the study are to identify the properties of pure biodiesel and cold flow improver, and to simulate the viscosity, density and pour point of CFI blended biodiesel. Besides, this study emphasizes to obtain the optimum correlation among the blended biodiesel properties that can provide accurate simulation results for certain range.

\subsection{METHODOLOGY}

\subsection{Overview}

This research introduces a 5-phase approach as shown in Figure 1. The research started with identifying the characteristics of palm oil biodiesel, which was represented by one of the major components in the palm oil biodiesel - methyl palmitate, and also ethanol as CFI in the study by using TmoleX18 and COSMOthermX software. The second phase started with the viscosity and density blending of ethanol and biodiesel using Grunberg-Nissan equation [11]. Next, the simulation of PP was done by using Riazi and Daubert equation [12] at various combinations of viscosities and densities at different temperatures. Then, the optimum blended cold flow properties were identified and verified by comparing the simulation results and experimental results from literature.

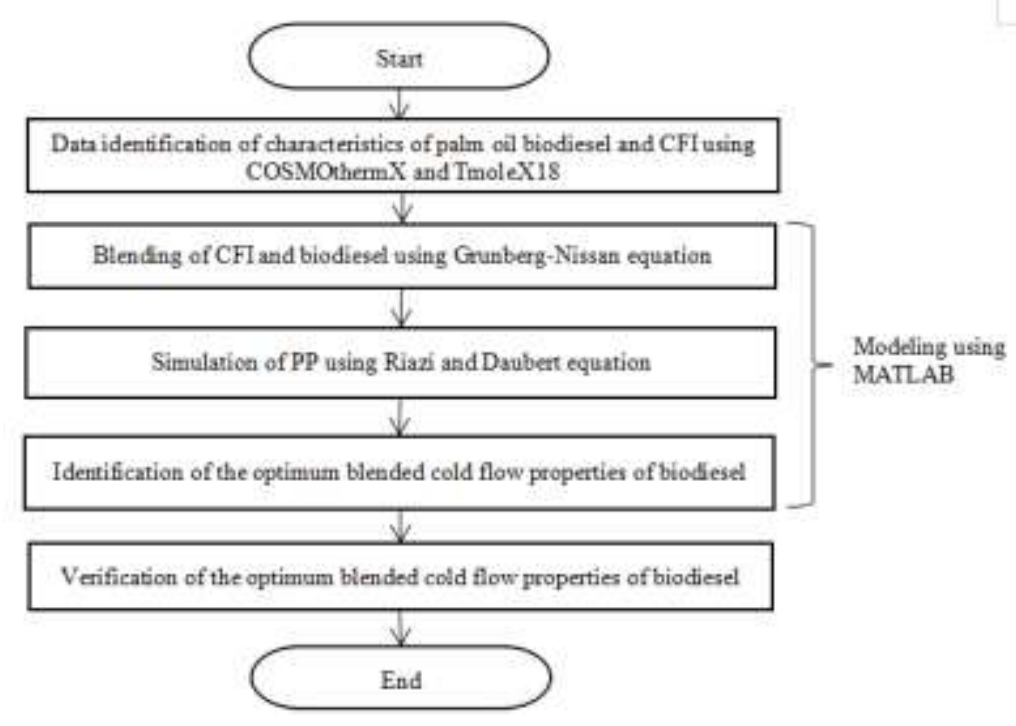

Figure 1 Overview of methodology

\subsection{Blending of CFI and Biodiesel using Grunberg-Nissan equation}

In this study, the CFI, ethanol was added to biodiesel in mole ratio of 0.0 to 0.2 by the increase of 0.02 of ethanol. The composition of ethanol was limited to 0.2 to ensure the quality and purity of biodiesel. For the prediction of density of ethanol blended biodiesel, $\rho$ it was calculated using equation (1) where $\rho_{i}$ and $m_{i}$ are density and mass respectively, of component $\mathrm{i}(\mathrm{i}=1$ or 2 ) in the binary blends, representing ethanol and biodiesel, respectively.

$$
\rho=\frac{m_{1}+m_{2}}{\frac{m_{1}}{\rho_{1}}+\frac{+m_{2}}{\rho_{2}}}
$$

For the prediction of viscosity of ethanol blended with biodiesel, Grunberg-Nissan equation (2) uses one interaction parameter to estimate changes in the dynamic viscosity, $\mu$ of binary liquid mixtures caused by molecular interactions. The content of each component is quantified by its mole fraction $\left(x_{1}\right)$, dynamic viscosity $\left(\mu_{1}\right)$, volume fraction $\left(z_{1}\right)$ and density $\left(\rho_{1}\right)$ for ethanol while $x_{2}, \mu_{2}, z_{2}$ and $\rho_{2}$ for methyl palmitate, respectively. Interaction coefficient, $G_{12}$ for ethanolbiodiesel blend stated in [11] is 1.4.

$$
\mu=\frac{\exp \left(x_{1} \ln \rho_{1} \mu_{1}+x_{2} \ln \rho_{2} \mu_{2}+x_{1} x_{2} G_{12}\right)}{z_{1} \rho_{1}+z_{2} \rho_{2}}
$$




\subsection{Simulation of PP using Riazi and Daubert equation}

$P P$ is defined as the lowest temperature at which the oil will flow when it is cooled without stirring under standard cooling conditions. In this research, $P P$ of ethanol blended biodiesel was estimated by using Riazi and Daubert equation (3), which is used to estimate the $P P$ for petroleum fractions:

$$
P P=130.47 S G^{2.970566} M^{(0.61235-0.473575 S G)} v_{\text {blended }}^{(0.310331-0.328345 S G)}
$$

where $P P$ is in kelvin, $M$ is the molecular weight and $v$ is kinematic viscosity in cSt. $P P$ were estimated at various combinations of viscosities and densities of ethanol blended biodiesel, such as viscosity at temperature $10{ }^{\circ} \mathrm{C}$ and $20{ }^{\circ} \mathrm{C}$ and density at temperature $-5^{\circ} \mathrm{C}, 10^{\circ} \mathrm{C}$ and $30^{\circ} \mathrm{C}$ in MATLAB software to simulate the closest data with the experimental results from [13].

\subsection{RESULTS AND DISCUSSION}

\subsection{Data identification of characteristics of palm oil biodiesel and ethanol}

The viscosities and densities of pure palm oil biodiesel and ethanol were determined by using TmoleX18 and COSMOthermX software at temperature range from $-5^{\circ} \mathrm{C}$ to $30{ }^{\circ} \mathrm{C}$. The results are tabulated as shown in Table 1 .

Table 1. Viscosities and densities of methyl palmitate and ethanol

\begin{tabular}{ccccc}
\hline $\begin{array}{c}\text { Temperature } \\
\left({ }^{\circ} \mathbf{C}\right)\end{array}$ & $\begin{array}{c}\text { Viscosity of Methyl } \\
\text { Palmitate } \\
(\mathbf{c P})\end{array}$ & $\begin{array}{c}\text { Viscosity of } \\
\text { Ethanol } \\
(\mathbf{c P})\end{array}$ & $\begin{array}{c}\text { Density of } \\
\text { Methyl Palmitate } \\
(\mathbf{g} / \mathbf{m l})\end{array}$ & $\begin{array}{c}\text { Density of } \\
\text { Ethanol } \\
(\mathbf{g} / \mathbf{m l})\end{array}$ \\
\hline 30 & 10.938 & 2.103 & 0.859 & 0.773 \\
25 & 14.239 & 2.522 & 0.864 & 0.778 \\
20 & 18.704 & 3.043 & 0.869 & 0.782 \\
15 & 24.802 & 3.696 & 0.874 & 0.787 \\
10 & 33.218 & 4.519 & 0.879 & 0.792 \\
5 & 44.959 & 5.566 & 0.883 & 0.797 \\
0 & 61.528 & 6.909 & 0.888 & 0.801 \\
-5 & 85.194 & 8.644 & 0.893 & 0.806 \\
\hline
\end{tabular}

In contrast to the viscosity of ethanol, the results show that the viscosity of biodiesel increases significantly with the decrease of temperature as the cohesive force of a substance is inversely proportional to the temperature. Therefore, the cohesive forces of methyl palmitate and ethanol increase when the temperature decreases, resulting the increase of dynamic viscosity. On the other hand, the density of biodiesel and ethanol increases with the decrease of temperature, as the decrease of kinetic energy can cause lesser molecular motion, which results in the molecular weight per unit volume increases [14].

\subsection{Results of CFI and Biodiesel Blending using Grunberg-Nissan equation}

The graphs of viscosities and densities blended, respectively versus different temperatures are shown in Figure 2 and Figure 3.

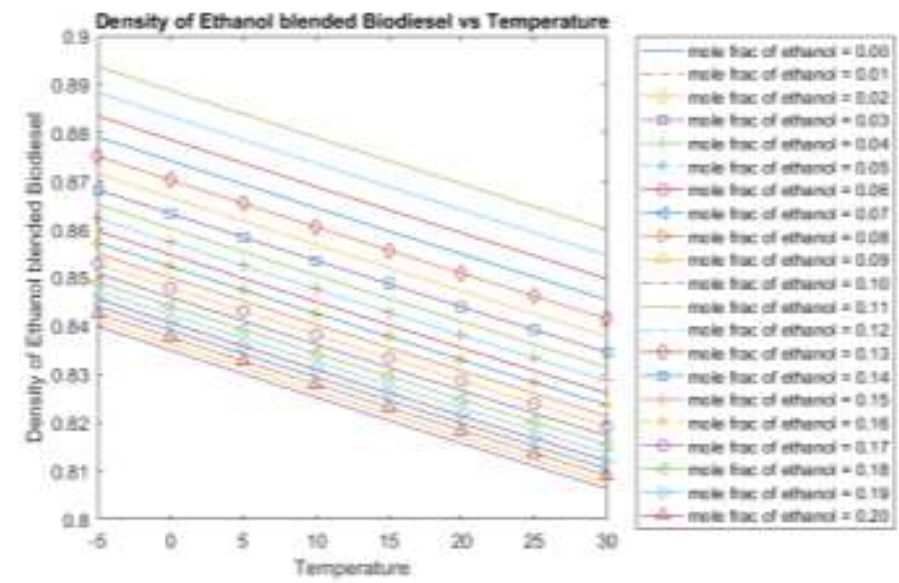

Figure 2. Densities of different mole fractions of ethanol blended biodiesel versus temperature 


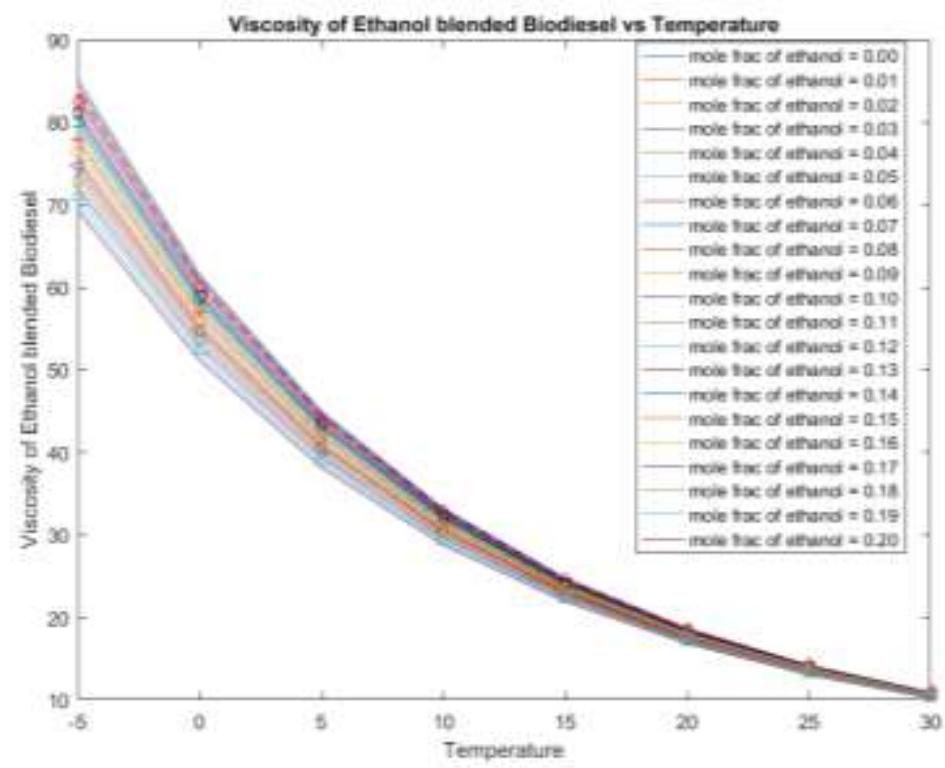

Figure 3. Viscosities of different mole fractions of ethanol blended biodiesel versus temperature

The results suggest that the density and dynamic viscosity of blended biodiesel with addition of 0.2 mole fraction of ethanol are the lowest among the others while pure biodiesel has the highest density and dynamic viscosity without any CFI. This is because ethanol has low cohesive force, which causes the blending of ethanol and biodiesel to be decreased with the increase of mole fraction of ethanol. Besides, with the increase of addition of ethanol, the interaction between inter-molecules of methyl palmitate decreases and causes the lowering of cohesive force, resulting in decrease of dynamic viscosity of blended biodiesel. Besides, with the increase of mole fraction of ethanol, the density of blended biodiesel decreases as the biodiesel become lesser packed with the addition of ethanol molecules. Therefore, the results suggest that CFI such as ethanol can significantly lower the density and viscosity of biodiesel.

\subsection{Results of PP Simulation using Riazi and Daubert equation}

The PP simulation at various combinations of viscosities and densities of blended biodiesel using Riazi and Daubert equation is as shown in Figure 4.

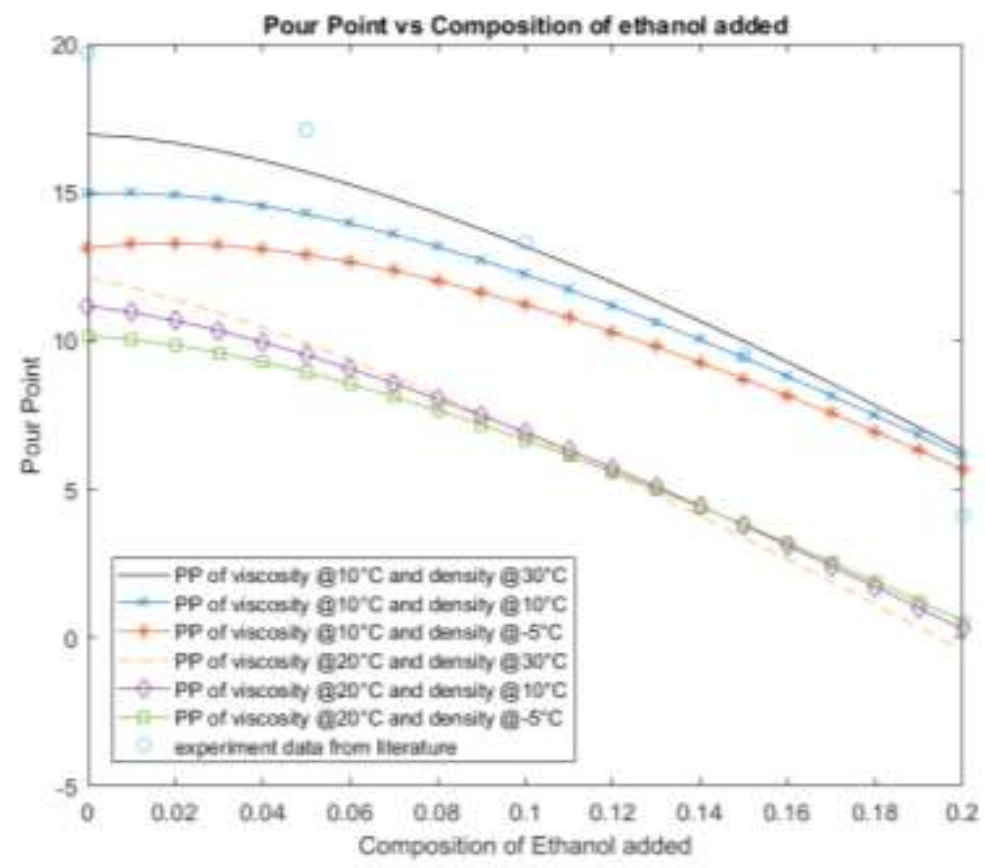

Figure 4. PP at various combinations of viscosities and densities of blended biodiesel at different temperature versus composition of ethanol added into biodiesel 
Based on the results obtained from Figure 3, the PP with viscosity at $10^{\circ} \mathrm{C}$ and density at $30^{\circ} \mathrm{C}$ showed the closest results compared to the experimental data from literature. The dynamic viscosity has more significant effect to predict PP compared to density, as it affects the shear rate of the blended biodiesel. The shear rate affects the flowability of the blended biodiesel, therefore $10^{\circ} \mathrm{C}$ is chosen to be the optimum temperature for viscosity to predict PP as it measures the appropriate flowability of the blended biodiesel. The results suggest that the equation from Riazi and Daubert is appropriate to predict PP for ethanol-biodiesel blend with optimum combinations of blended dynamic viscosity and density at $10^{\circ} \mathrm{C}$ and $30^{\circ} \mathrm{C}$, respectively.

\subsection{Verification of the optimum blended biodiesel CFP}

To verify the accuracy of blended biodiesel CFP, errors are calculated by compared the simulation results to the experimental results as shown in Figure 5

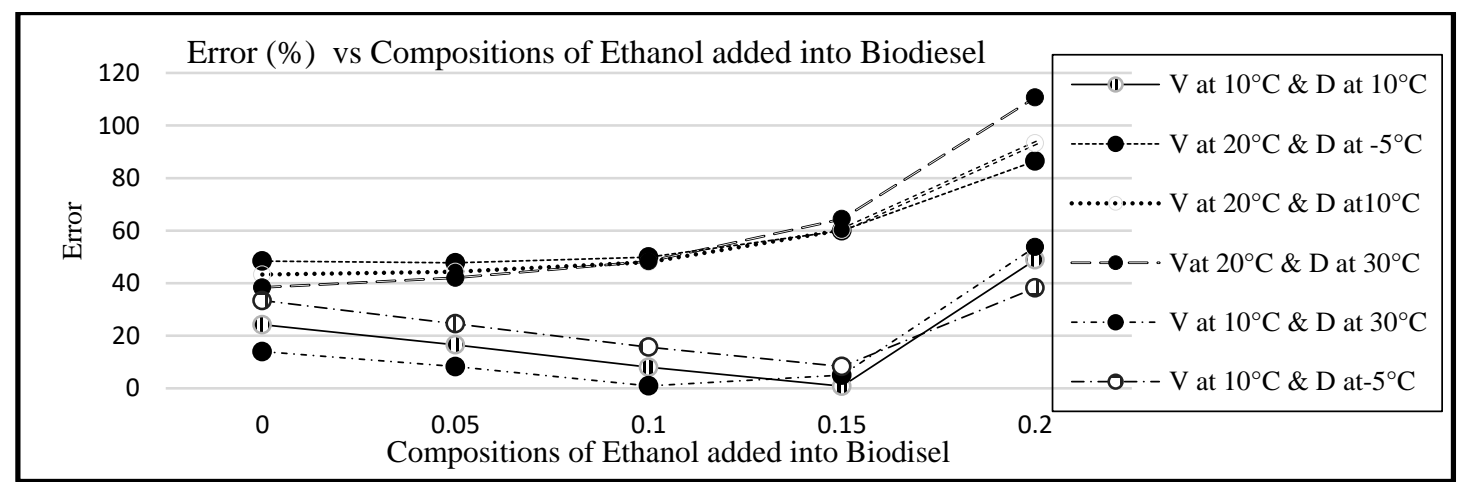

Figure 5. Graph of error (\%) versus compositions of ethanol added into biodiesel at various combinations of viscosities, $\mathrm{V}$ and densities, $\mathrm{D}$ of blended biodiesel

The results show that the PP with viscosity at $10^{\circ} \mathrm{C}$ and density at $30^{\circ} \mathrm{C}$ showed the closest results compared to the experimental data from literature [13] as it has the least errors compared to other combinations, which is $0.92 \%$ of simulation error at 0.1 mole fraction of ethanol. Therefore, the results suggest that the equation from Riazi and Daubert is suitable to simulate the PP for ethanol-biodiesel blend with optimum combinations of dynamic viscosity and density at $10^{\circ} \mathrm{C}$ and $30^{\circ} \mathrm{C}$, respectively.

\subsection{CONCLUSION}

In conclusion, biodiesel which derived from vegetable oil or animal fats, is introduced as alternative for petroleum-based diesel as it has very similar characteristics of diesel, but it also has renewable, biodegradable and environmentally acceptable profile. However biodiesel is poor in CFP which can give rise to thickening of biodiesel, resulting in the clogging of fuel filters. Therefore this study's main purpose is to determine the optimum properties of blended biodiesel that provides the most accurate simulation results of CFP of the blended biodiesel.

The properties of pure biodiesel and ethanol were successfully determined by using TmoleX18 and COSMOthermX software. The viscosity, density and pour point of blended biodiesel were simulated successfully using Grunberg-Nissan equation and, Riazi and Daubert equation at $-5^{\circ} \mathrm{C}$ to $30^{\circ} \mathrm{C}$ with the compositions of 0 to 0.2 ethanol added. The optimum combination of viscosities and densities of blended biodiesel for the blended cold flow properties is at $10^{\circ} \mathrm{C}$ and $30^{\circ} \mathrm{C}$ respectively with $0.92 \%$ of simulation error at 0.1 mole fraction of ethanol.

\section{Acknowledgements}

This work was financially supported by Ministry of Higher Education Malaysia and Universiti Teknologi Malaysia under the UTM Encouragement Research Grants Q.J130000.3851.19J32.

\section{References}

[1] Dwivedi, G., and M. P. Sharma. 2014. Impact of cold flow properties of biodiesel on engine performance. Renewable and Sustainable Energy Reviews, 31: 650-656.

[2] Meher, L. C., D. Vidya Sagar, and N. S. Naik. 2006. Technical aspects of biodiesel production by transesterification-a review. Renewable and Sustainable Energy Reviews, 10(3): 248-268. 
[3] Zhang, Y., M. A. Dubé, D, D, McLean, and M. Kates. 2003. Biodiesel production from waste cooking oil: 2. Economic assessment and sensitivity analysis. Bioresource Technology, 90(3): 229-240.

[4] Saxena, P., S. Jawale, and M. H. Joshipura. 2013. A Review on Prediction of Properties of Biodiesel and Blends of Biodiesel. Procedia Engineering, 51: 395-402.

[5] Boshui, C., S. Yuqiu, F. Jianhua, W. Jiu, and W. Jiang. 2010. Effect of cold flow improvers on flow properties of soybean biodiesel. Biomass and Bioenergy, 34(9): 1309-1313.

[6] Wang, J., Cao, L., and Han, S. (2014). Effect of polymeric cold flow improvers on flow properties of biodiesel from waste cooking oil. Fuel, 117: 876-881

[7] Altaie, M. A. H., Janius, R. B., Rashid, U., Taufiq Yap, Y. H., Yunus, R., and Zakaria, R. (2015). Cold flow and fuel properties of methyl oleate and palm-oil methyl ester blends. Fuel. 160: 238-244.

[8] Cao, L., Wang, J., Liu, C., Chen, Y., Liu, K., and Han, S. (2014). Ethylene vinyl acetate copolymer: A bio-based cold flow improver for waste cooking oil derived biodiesel blends. Applied Energy, 132: 163-167.

[9] Cao, L., Wang, J., Liu, K., \& Han, S. (2014). Ethyl acetoacetate: A potential bio-based diluent for improving the cold flow properties of biodiesel from waste cooking oil. Applied Energy, 114: 18-21.

[10] Makarevičienè, V., Kazancev, K., and Kazanceva, I. (2015). Possibilities for improving the cold flow properties of biodiesel fuel by blending with butanol. Renewable Energy, 75: 805-807.

[11] Lapuerta, M., J. Rodriguez-Fernandex, D. Fernandex-Rodriguez, and R. Patino-Camino. 2017. Modeling viscosity of butanol and ethanol blends with diesel and biodiesel fuels. Fuel, 199: 332-338.

[12] Riazi, M. R. 2005. Characterization and Properties of Petroleum Fractions, Philadelphia, PA. American Society for Testing and Materials (ASTM).

[13] Verma, P., M. P. Sharma, and G. Dwivedi. 2016. Evaluation and enhancement of cold flow properties of palm oil and its biodiesel. Energy Reports, 2: 8-13.

[14] Ramirez Verduzco, L. F. 2013. Density and viscosity of biodiesel as a function of temperature: Empirical models. Renewable and Sustainable Energy Reviews, 19: 652-665. 